\title{
EXPERIMENTAL RESEARCH OF INFLUENTIAL PARAMETERS ON SPRINGBACK IN BENDING OF STAINLESS STEEL
}

\author{
GUSEL, L.
}

Abstract: Springback is generally defined as the elastic recovery of material after a bending process and remains the fundamental problem of the sheet metal forming processes, especially bending. Control of springback for the bending processes applied in practice is difficult especially because of many influential parameters. Accurate determination of the springback of metal sheets is of crucial importance for the product quality and tool design. The main objective of the paper is to evaluate the impact of various influential process parameters, such as material thickness, punch radius, die opening and the load time on springback of two different stainless steels. A detailed experimental study has been performed on ferritic and martensitic stainless steel. Five different material thicknesses, four punch radius, three die openings and different load times were used to investigate their influence on springback values. The obtained results are presented as graphs and diagrams which help us to determine the influence of different parameters on springback and to choose the most suitable parameters for effective bending process of stainless steels.

Key words: Metal forming, sheet bending, springback, stainless steel
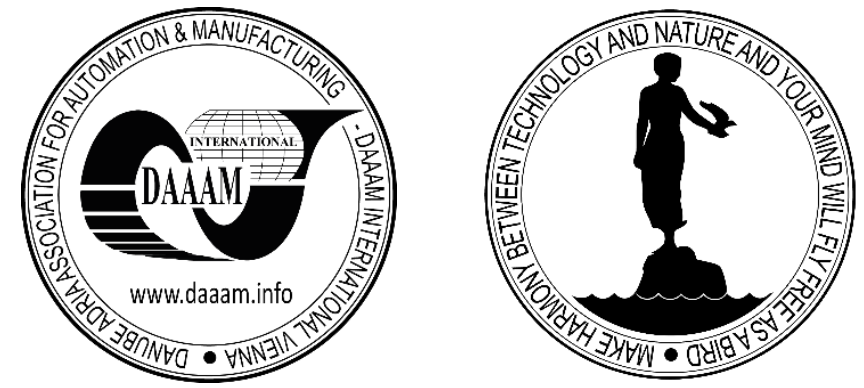

Authors' data: Assoc. Prof. Dr. Gusel, L[reo]; University of Maribor, Faculty of Mechanical Engineering, Smetanova 17, 2000, Maribor, Slovenia, leo.gusel@um.si.

This Publication has to be referred as: Gusel, L[eo] (2019). Experimental Research of Influential Parameters on Springback in Bending of Stainless Steel, Chapter 03 in DAAAM International Scientific Book 2019, pp.033-042, B. Katalinic (Ed.), Published by DAAAM International, ISBN 978-3-902734-24-2, ISSN 1726-9687, Vienna, Austria

DOI: $10.2507 /$ daaam.scibook.2019.03 


\section{Introduction}

In bending process, which is used in various sheet metal products limits of material elasticity can be exceeded. Because materials have a finite elasticity modulus, plastic deformation is followed by a certain value of elastic recovery after removing the load. Therefor the material tries to retrieve its original form after bending process. This phenomenon is called springback and is one of the most important parameter to impact the quality of bent products. It depends on material characteristics and various process parameters and has an important role in tooling and process planning. Precise knowledge of the influential parameters and the determination of precise values of springback is vital for successful production and achieving a quality product especially when using stainless steel, which is known to have very high values of springback in bending process.

Although the theory of sheet bending provides a good knowledge of mechanism of springback, because of large number of influencing parameters in bending process it is still difficult to obtain the accurate analytical solutions. The execution of experiments is inevitable to determine the impact of crucial parameters on springback. Many authors have experimentally analyzed impact of different bending process parameters on springback values (D'Ursol et al., 2007; Buang et al., 2015; Shakir et al., 2012). Other have focused on theoretical analysis of springback mechanism (Zhang et al., 2013; Dai et al., 2017). An optimization method using the reduced basis technique for sheet metal bending process was described in paper (Jabbari et al., 2014) for reducing the springback angles. In paper (Daw-Kwei, 2018) the influence of process parameters, such as punch radius, material strength and normal anisotropy, on springback radius ratio for a high strength steel were researched experimentally, while in the paper (Juraga et al., 2011) influence of cold forming on mechanical properties of stainless steel was analysed. According to results obtained in paper (Tekaslan et al., 2008) thickness of sheet metal and the application time duration of the punch load have a great impact on the springback values. Higher duration of the punch load and decrease of bending angle decreases the springback value. Springback behavior and selection of optimal process parameters by finite element method and experiments is described in (Ramadass et al., 2019). In this research the most influential parameter was sheet thickness, close followed by punch radius. Also, analysis of variance was performed to obtain the impact of process parameter. In research paper (Khal etal., 2016) the influence of different current parameters such as current density and current duration on springback of bent stainless steel is presented. Simulation of V-die bending by using finite element method was described in paper (Kartik et al., 2017) to identify the impact of different process parameters that have greatest significance on the springback of the bent material. Research paper (Gusel, 2011) describes the influence of effective strain on springback. Increase of effective strain causes increase of springback values. Springback in V-bending of aluminium with one clamped end and other end free has been investigated in paper (Chan et al., 2004). Different die and punch parameters and punch angles were used. An increase of springback with increasing punch angle was found out as a result of experiments. 
Finite element method was used in paper (Dilipak et al., 2013) where impact of material characteristics and different punch radius values were studied in the bending of 1.0038 steel as well as the impact of normalizing and tempering. Authors in (Dezelak et al., 2014) investigated the effect of rolling directions of strips of dual phase steel on twist springback values. In (Mohammadi et al., 2015) air bending experiments were performed on laminated Al-sheets using different values of punch struck, die opening, and punch radius to obtain springback values. It was found out that the most influential parameter was die opening.

In this paper extensive experimental analysis of the impact of various influential bending process parameters, such as material thickness, punch radius, die opening and the bending load time on springback of two different stainless steels is presented. Obtained results are very important for successful control and parameter optimization of bending process.

\section{Springback after bending}

During bending the load is applied to bend the part in the desired shape. The part is bent for a certain angle and bend radius by bending tool. After bending, when the tool is removed, there is a dimensional change of the bent part as presented in Fig. 1. Springback is the elastic recovery of plastically deformed material which causes geometry changes and loss of dimensional accuracy of the bent part.

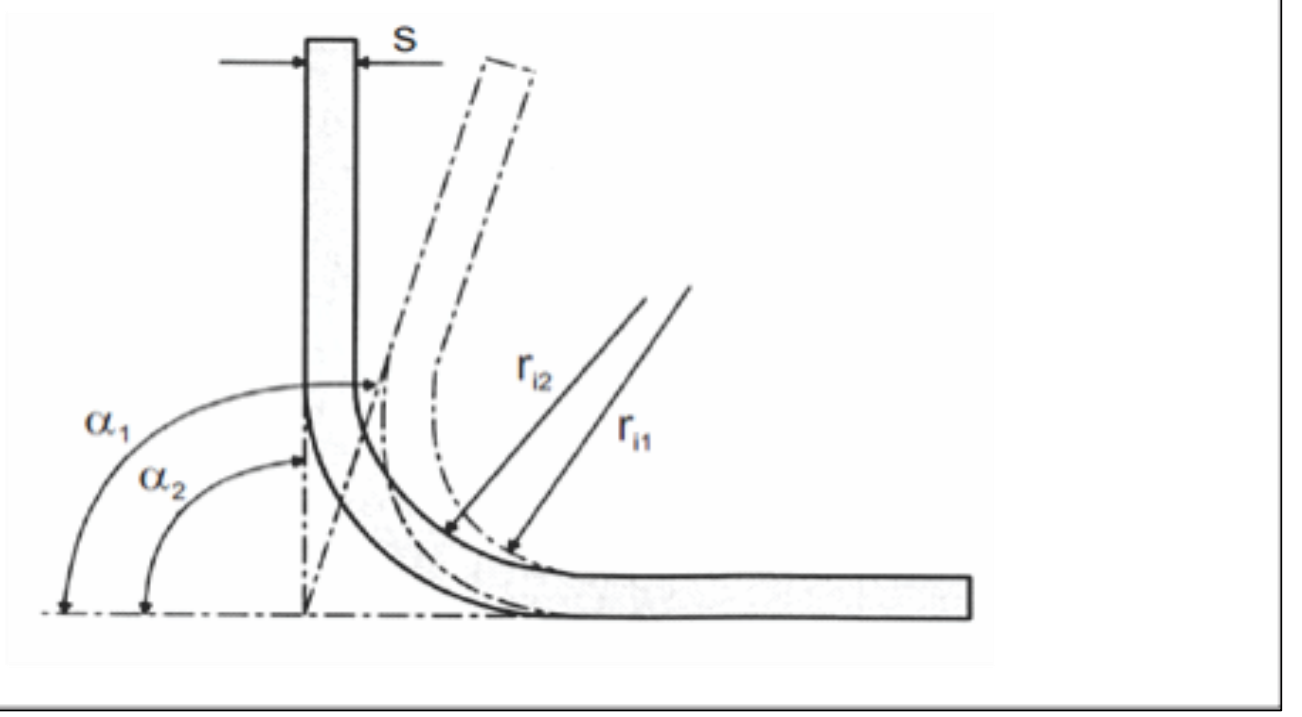

Fig. 1. Schematic illustration of springback

On Fig. $1 r_{\mathrm{i} 1}$ is bend radius before springback and $r_{\mathrm{i} 2}$ after springback, $\alpha_{1}$ is bend angle before springback and $\alpha_{2}$ after springback while $s$ is the thickness of the material. The springback value can be determined either by springback angle $\Delta \alpha$ (2) or springback factor $K(1)$, which represents the ratio between the bend angle $\alpha_{2}$ and $\alpha_{1}$. The expression for springback factor $K$ is given as (Lange, 1994): 
Gusel, L.: Experimental Research of Influential Parameters on Springback in Bendi...

$$
K=\frac{r_{i 2}+s / 2}{r_{i 1}+s / 2} \quad \text { or } \quad K=\frac{\alpha_{2}}{\alpha_{1}}
$$

Springback angle can be calculated from the difference between two angles:

$$
\Delta \alpha=\alpha_{1}-\alpha_{2}=\left(\frac{1}{K}-1\right) \alpha_{2}
$$

Springback is influenced by many different parameters such as material's yield strength and Young modulus, strain hardening, material width and thickness, die opening, punch radius, die radius, bend angle, velocity of the punch, load time, etc. It can't be completely eliminated, so at least it must be compensated. In bending process, springback is usually compensated by over bending the part.

\section{Experimental setup}

The main objective of the experimental work was the determination and evaluation of the influence of various process parameters in bending such as, punch radius, die opening, material thickness and the load time on springback of two different stainless steels - martensitic stainless steel 1.4057 and ferritic stainless steel 1.4016. Both steels have excellent corrosion resistance, good ductility, impact toughness and formability. The martensitic stainless steel has a wide application in machine building industry, automotive industry, ship and pump parts, as tool steel for the glass industry, etc. Typical applications for ferritic stainless steel are electronic equipment, building industry, food and beverage industry and mechanical engineering. The chemical composition of both stainless steels is presented in Table 1.

\begin{tabular}{|c|c|c|c|c|c|c|c|}
\hline steel & $\mathrm{C}$ & $\mathrm{Si}$ & $\mathrm{P}$ & $\mathrm{Mn}$ & $\mathrm{S}$ & $\mathrm{Cr}$ & $\mathrm{Ni}$ \\
\hline 1.4057 & $0,2 \%$ & $0,8 \%$ & $0,04 \%$ & $0,9 \%$ & $0,02 \%$ & $17 \%$ & $1,9 \%$ \\
\hline 1.4016 & $0,1 \%$ & $0,9 \%$ & $0,03 \%$ & $0,8 \%$ & $0,01 \%$ & $17 \%$ & - \\
\hline
\end{tabular}

Tab. 1. Chemical composition of stainless steels.

Tensile tests were performed to obtain most important mechanical characteristics of both steels. Results are presented in Tab. 2 from which the great difference especially in tensile and yield strength can be observed.

\begin{tabular}{|c|c|c|c|c|}
\hline St. Steel & $\begin{array}{c}\text { Yield } \\
\text { strength } \mathrm{R}_{\mathrm{m}} \\
{\left[\mathrm{N} / \mathrm{mm}^{2}\right]}\end{array}$ & $\begin{array}{c}\text { Tensile } \\
\text { strength } \mathrm{R}_{0,2} \\
{\left[\mathrm{~N} / \mathrm{mm}^{2}\right]}\end{array}$ & $\begin{array}{c}\text { Elongation } \\
\mathrm{A}_{5} \\
{[\%]}\end{array}$ & $\begin{array}{c}\text { Modulus of } \\
\text { elasticity E } \\
{\left[\mathrm{N} / \mathrm{mm}^{2}\right]}\end{array}$ \\
\hline 1.4057 & 605 & 820 & 15,5 & 216000 \\
\hline 1.4016 & 296 & 495 & 24,5 & 220000 \\
\hline
\end{tabular}

Tab. 2. Mechanical properties of stainless steel. 
Large number of experimental specimens (strips for bending tests) were made from both steels by cutting along rolling direction. Dimensions for all specimens were $140 \mathrm{~mm} \times 30 \mathrm{~mm}$. Bending was performed in special bending tool where specimens were carefully centered in the way that punch bent the specimens exactly in the middle. After the bending the punch immediately returned to the starting position, so that the bending load time was less than one second. Values of angle before and after bending for every specimen were precisely measured with digital and optical measuring equipment. The difference between bending angles was measured on both arms of the bent specimen to eliminate the possibility of punch misalignment. The specimens didn't have contact with side walls or the bottom of the die during bending - essentially it was an air V-type of bending. This is important to avoid the impact on springback, due to the squeezing of specimens in the bending area.

The experiments were carried out at room temperature. The specimens were not lubricated, the punch speed was set to $20 \mathrm{~mm} / \mathrm{s}$ and stroke was $15 \mathrm{~mm}$. Universal die with different die openings and four different bending punches used in the experimental work are presented in Fig. 2.

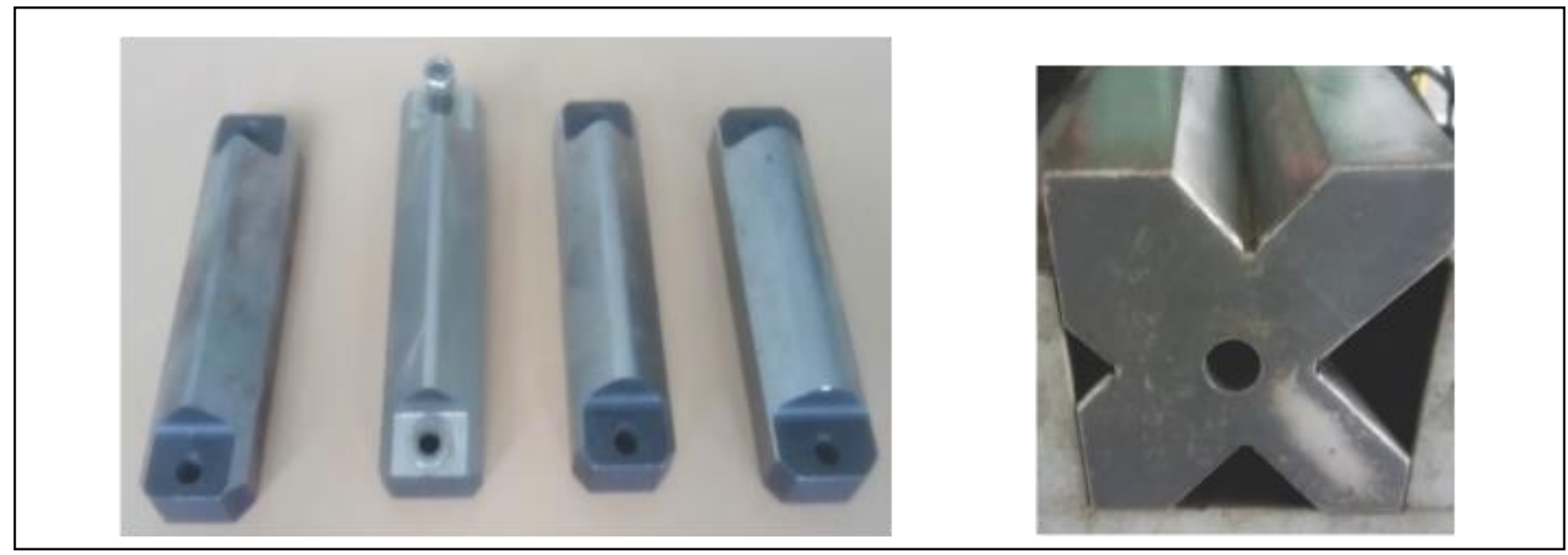

Fig. 2. Bending punches (left) and bending die (right).

Five different material thicknesses, four different punch radius and three different die openings were chosen for experiments. In addition, the influence of bending load time on springback was also analyzed for 1.4057 stainless steel. This time the punch was lowered completely until the specimens didn't reach the bottom of the $\mathrm{V}$ - die and then the punch remained in the lowest position for longer time. The values of all used parameters in experimental work are presented in Tab. 3.

\begin{tabular}{|c|c|}
\hline Parameter & Value variation \\
\hline Material thickness $s[\mathrm{~mm}]$ & $\begin{array}{lllll}0,9 & 1,2 & 1,5 & 2,0 & 2,5\end{array}$ \\
\hline Punch radius $r_{\mathrm{p}}[\mathrm{mm}]$ & $\begin{array}{lll}4 & 7 & 10 \\
\end{array}$ \\
\hline Die opening $w[\mathrm{~mm}]$ & 40 \\
\hline Punch velocity $v_{p}[\mathrm{~mm}]$ & 20 \\
\hline Bending load time $t[\mathrm{~s}]$ & $\begin{array}{llllll}5 & 10 & 15 & 25 & 40 & 60 \\
\end{array}$ \\
\hline
\end{tabular}

Tab. 3. Different parameters used in bending process. 
In total more than 70 experiments were performed for precise analysis of impact of different influential parameters on springback of stainless steels. The greatest limitation of our research was that we didn't analyze the influence of even more parameters, for example punch velocity, die radius or punch stroke.

\section{Results and discussion}

Results obtained in extensive experimental analysis of the influence of material thickness, punch radius, die opening and the bending load time on springback of two stainless steels with very different yield and tensile strengths are presented in Fig. 3 to Fig. 6. The influence of material thickness on the springback is shown in Fig. 3. With increasing thickness springback decreases for both steels. For 1.4057 steel the springback values decrease from $7,42^{\circ}$ for $0,9 \mathrm{~mm}$ thickness to $5,12^{\circ}$ when specimens of $2,5 \mathrm{~mm}$ thickness were used. A slightly lower fall of springback was measured for 1.4016 steel. With bigger die openings higher springback was obtained for the same specimens. It is obvious that the thickness of the material has a very important impact on springback.

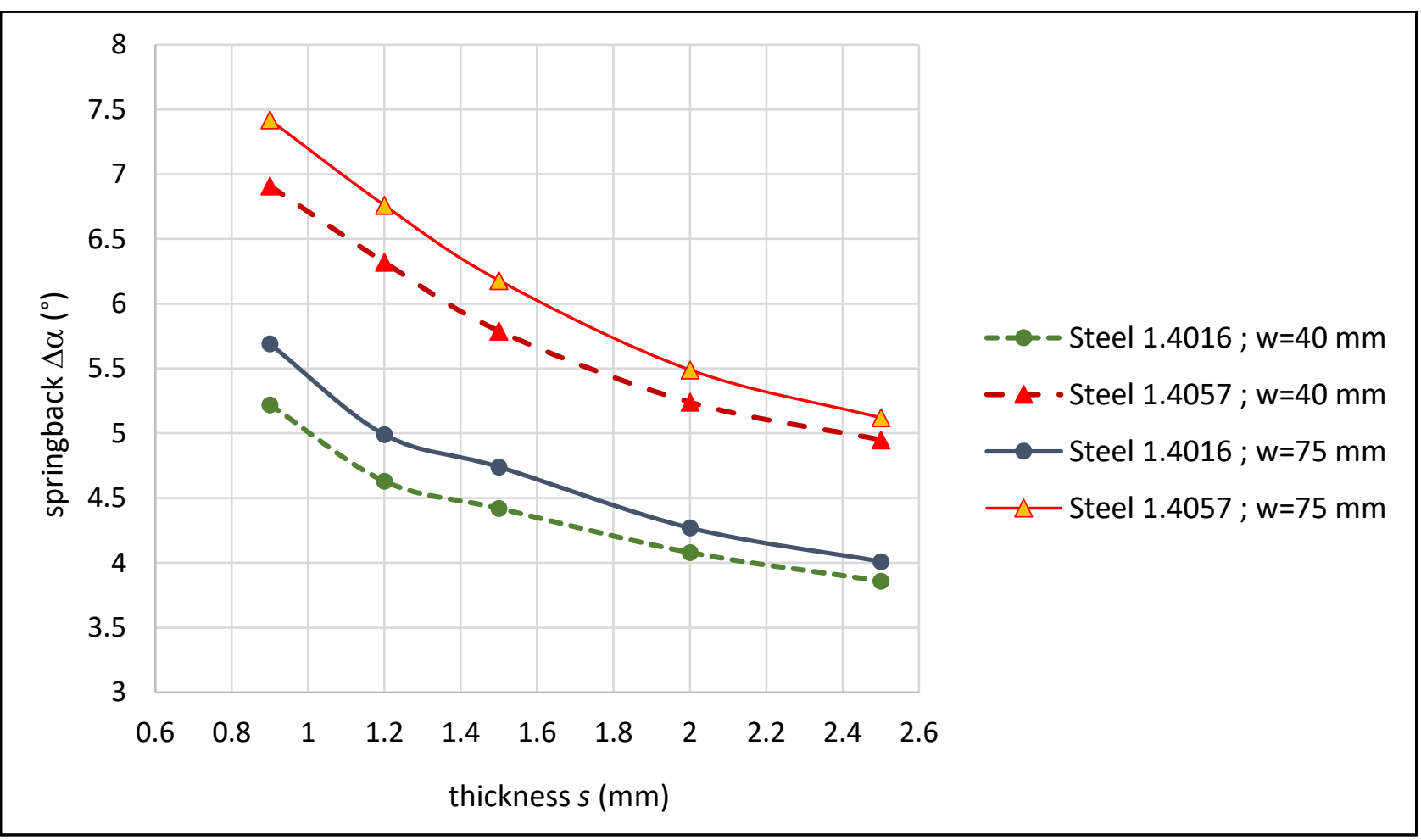

Fig. 3. The influence of material thickness on the springback $\left(r_{\mathrm{p}}=4 \mathrm{~mm}\right)$

The influence of punch radius on the springback of stainless steels for two different thicknesses is presented in Fig. 4. The highest and lowest value for thickness was chosen deliberately to analyse the greatest possible influence of punch radius. It is obvious that springback values increase with increasing punch radius for both steels and both material thicknesses. This happens because with greater punch radius the contact area between punch and sheet becomes larger. This increases the bending moment which causes a larger springback angle. 


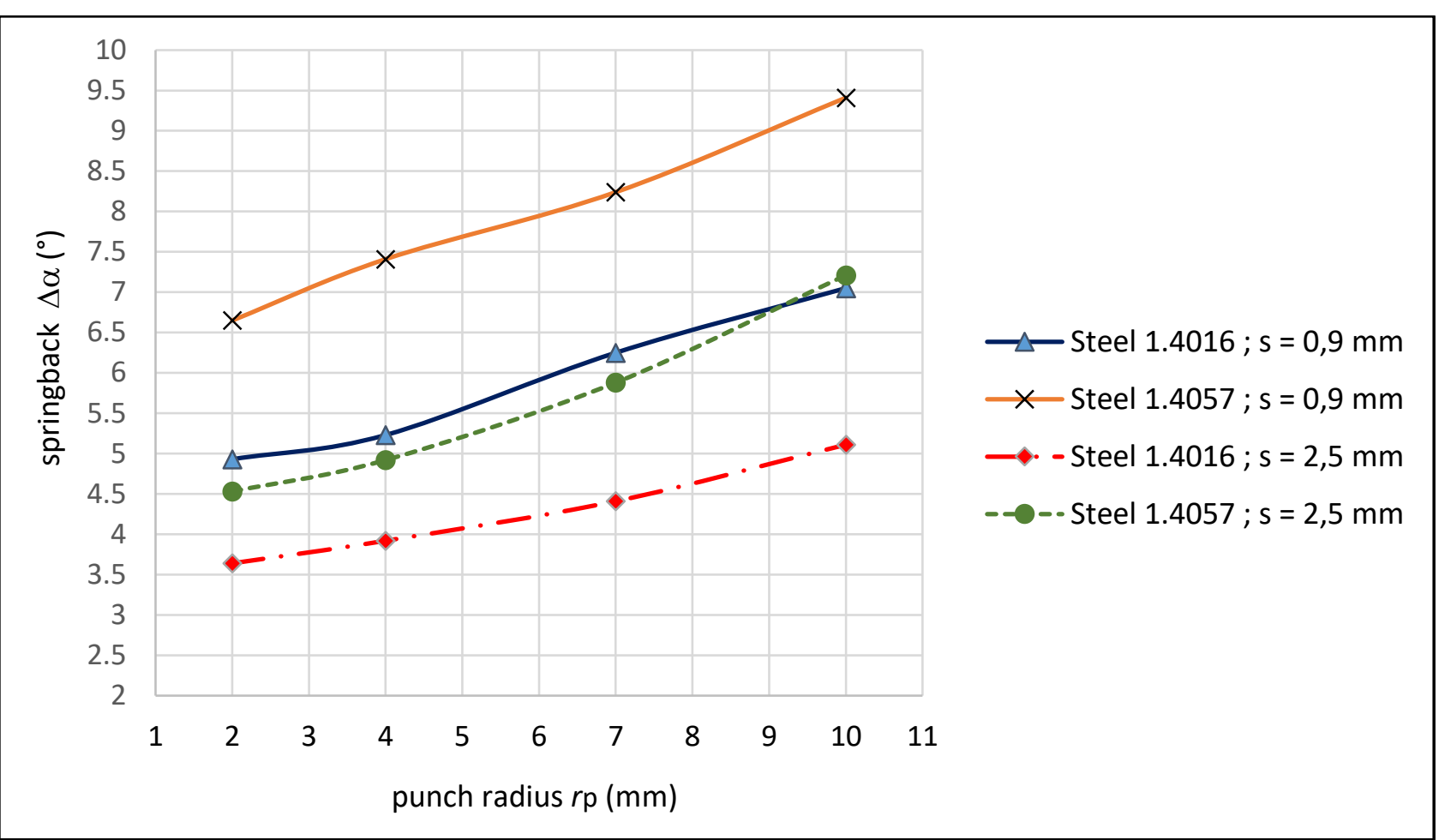

Fig. 4. The influence of punch radius on the springback $(w=55 \mathrm{~mm})$

The influence of punch radius on springback is very significant. When $0,9 \mathrm{~mm}$ strips of 1.4057 stainless steel were bent the increase of springback was nearly $45 \%$ (from $6,65^{\circ}$ at punch radius $r_{\mathrm{p}}=2 \mathrm{~mm}$ up to $9,4^{\circ}$ when the biggest punch radius $r_{\mathrm{p}}=$ $10 \mathrm{~mm}$ was applied). The same increase can also be observed for $2,5 \mathrm{~mm}$ strips of the same material. From the curvature of the curves, a slightly higher impact of the punch radius on a stainless steel with higher yield and tensile strength (1.4057) can be observed.

Fig. 5 shows influence of die opening on the springback for both stainless steels with strip thickness $s=0,9 \mathrm{~mm}$. Generally, it can be observed that with value increase of die opening springback also increases in all investigated cases. The reason for the increase is that the effective sheet length which is under deformation increases, this causes the total bending moment to increase which leads to an increase of springback. It is interesting to note that the influence of die opening is not so important than die radius or sheet thickness. On average, the springback increased by around $20 \%$ to 25 $\%$ when largest die opening was used $(w=75 \mathrm{~mm})$ compared to obtained springback values when die opening was $w=40 \mathrm{~mm}$. Another interesting finding is apparent from Fig. 5. Namely, with different parameters of the punch and die (tool geometry), almost identical values for the springback of two very different stainless steels (with different yield and tensile strength) were reached. This is yet another proof of the importance of an optimal choice of bending process parameters in order to reduce the springback.

The influence of bending load time on the springback for three different thicknesses of steel 1.4057 is presented in Fig. 6. With increase of bending load time the springback decreases for all investigated specimens. The bending time has the greatest impact on the reduction of the springback in the interval between $10 \mathrm{~s}$ and 25 s. In this area, the fall of the curve is very steep (great impact) then the steep slope gradually decreases. 
Gusel, L.: Experimental Research of Influential Parameters on Springback in Bendi...

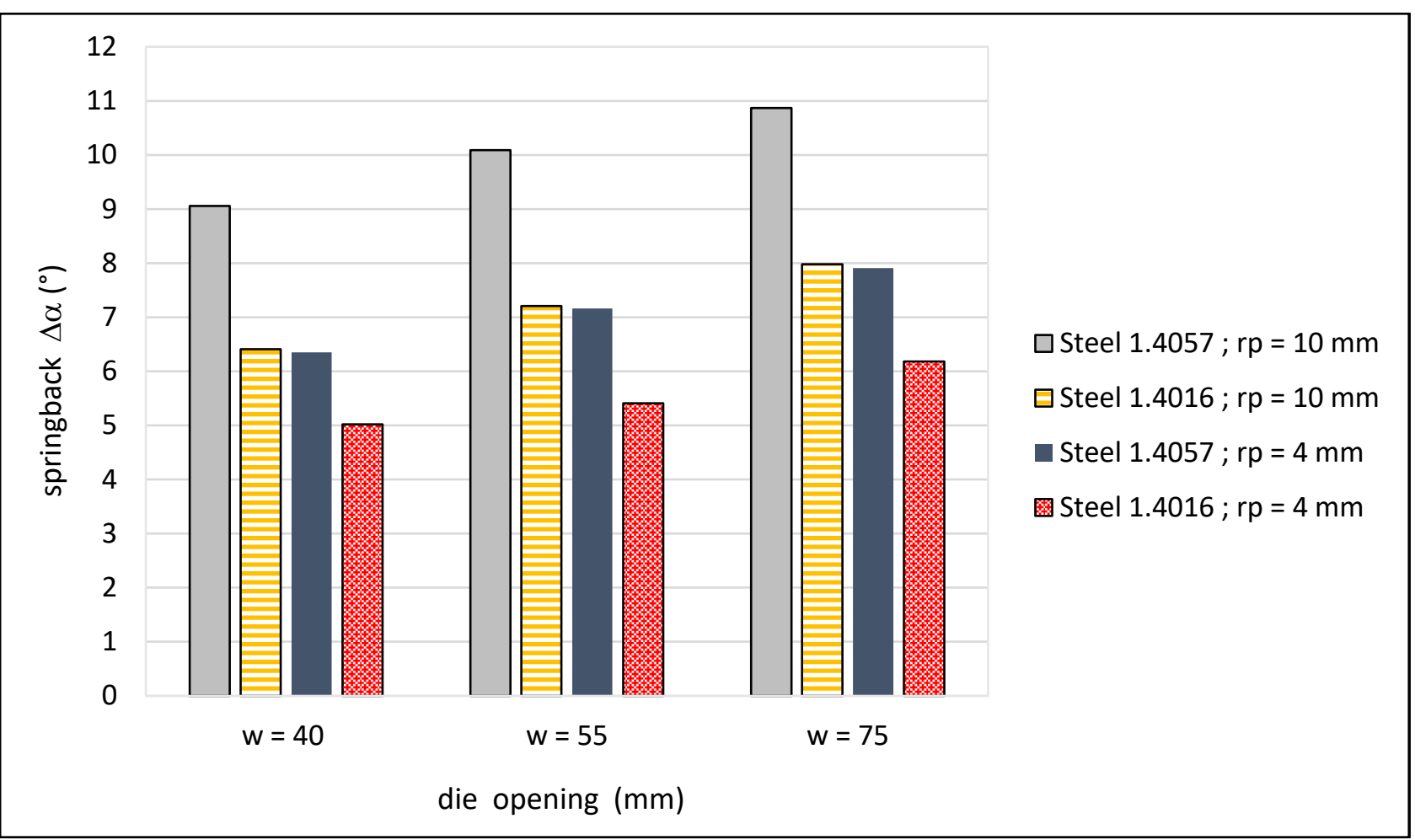

Fig. 5. The influence of die opening on the springback $(s=0,9 \mathrm{~mm})$

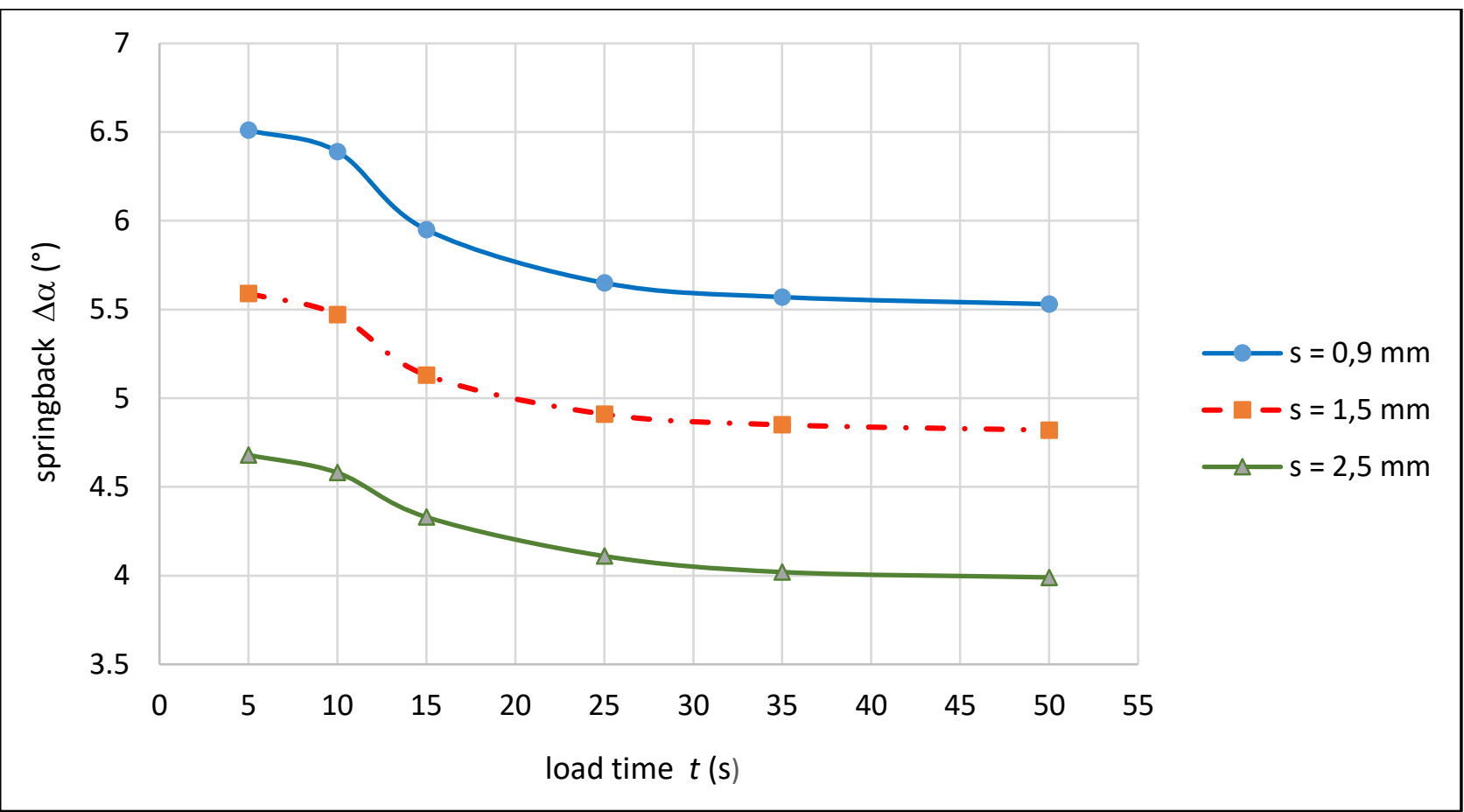

Fig. 6. The influence of bending load time $t$ on the springback of stainless steel 1. 4057 $\left(r_{\mathrm{p}}=4 \mathrm{~mm}, w=55 \mathrm{~mm}\right)$

The effect of bending load time is reduced after certain time and the prolongation of the loading time does not significantly affect springback. The impact of load time was greatest in the tiniest sheet metal - a total decrease of nearly $1^{\circ}$ in springback angle was obtained. Stopping the punch on the bent specimens for a definite period of time allows the elasticity of sheet metal to dispose. As result a lower value of the springback was obtained. 


\section{Conclusion}

One of the biggest problems in bending processes is springback phenomenon. In praxis it is very difficult to obtain the accurate springback, because material parameters such as elasticity, yield stress, hardening property, and process parameters such as thickness of sheet metal, die angle, punch radius and die opening affect springback in a very complex way. In this paper extensive experimental analysis of the influence of various bending process parameters on springback of two different stainless steels was presented.

The analysis of experimental results showed the following:

$\circ$ Depending on mechanical properties, interactions of investigated parameters have different influence on springback.

- Bent specimens of stainless steel with higher yield and tensile strength have larger springback values than bent specimens of stainless steel with lower yield and tensile strength.

- The thickness of the material is one of the key factors of influence. With a larger material thickness springback is smaller.

○ Another very influencing factor is punch radius. With the increase of the punch radius the springback also increases. When the punch radius increases, the force extends to a wider plastic area and this causes the increase of the springback.

- An increase of die opening causes increase of springback but the influence is not that large as that of material thickness or punch radius.

- The increase of bending load time affects the reduction of springback, but after a certain time the impact is significantly reduced.

By the help of the obtained results we can effectively control and influence the springback values and in this way increase the accuracy and quality of the bending process and bent products. In our future work we intend to analyze some additional process parameters that affect the springback and also to apply evolutionary computation methods for modelling the springback.

\section{References}

Buang, S.; Abdullah, S.A. \& Saedon, J. (2015). Effect of die and punch radius on springback of stainless steel sheet metal in the air V-die bending process. Journal of Mechanical Engineering and Sciences, Vol.8, pp. 1322-1331, ISSN: 2289-4659.

Chan, W.M.; Chew, H.I.; Lee H.P. \& Cheok, B.T. (2004). Finite element analysis of spring-back of V-bending sheet metal forming processes. Journal of Materials Processing Technology, Vol.148, No.1, pp. 15-24, ISSN: 0924-0136.

D'Ursol, G., Pellegrini. G. \& Maccarini, G. (2007). The effect of sheet and material properties on springback in air bending. Key Engineering Materials, Vol. 344, pp. 277284, ISSN: 1013-9826.

Dai, H.L.; Jiang, H.J.; Dai, T.; Xu, W.L. \& Luo, A.H. (2017). Investigation on the influence of damage to springback of U-shape HSLA steel plates. Journal of Alloys and Compounds, Vol. 708, pp. 575-586, ISSN: 0925-8388. 
Daw-Kwei, L. (2018). Relationship between mechanical properties and geometric parameters to limitation condition of springback based on springback-radius concept in V-die bending process. International Journal of Advanced Manufacturing Technology, Vol. 101, No.1-4, pp. 913-926, ISSN: 0268-3768.

Dezelak M., Stepisnik A., Pahole I. \& Ficko M. (2014). Evaluation of Twist Springback Prediction After an AHSS Forming Process. International Journal of Simulation Modelling, Vol. 13, No. 2, pp. 171-182, ISSN: 1726-4529.

Dilipak, H.; Özdemir, M. \& Sarikaya, M. (2013). Effects of material properties and punch tip radius on spring-forward in $90^{\circ} \mathrm{V}$ bending processes. Journal of Iron and Steel Research -International, Vol.20, No.10, pp. 64-69, ISSN: 1006-706X.

Gusel, L. (2011). Analysis of elastic recovery phenomena in bending process. Annals of DAAAM for 2011 \& Proceedings of the 22nd International DAAAM Symposium, Vienna 2011, Volume 22, No. 1, pp. 39-40, Katalinic, B. (edit.), ISSN:1726-9679. Jabbari, A. \& Shokooli, S. (2014). Springback reduction in sheet metal bending process. Indian Journal of Science research, Vol.2, pp. 400-403, ISSN: 0976-2876.

Juraga, I.; Alar, V.; Simunovic, V. \& Stojanovic, I. (2011). Influence of deformation induced martensite on brittleness of austenitic stainless steel. Annals of DAAAM for 2011 \& Proceedings of the 22nd International DAAAM Symposium, Vienna 2011, Volume 22, No. 1, pp. 1353-1354, Katalinic, B. (edit.), ISSN:1726-9679.

Kartik, T. \& Rajesh, R. (2017). Effect of punch radius and sheet thickness on springback in V-die bending. Advances in Natural and Applied Sciences, Vol.8, pp. 178-183, ISSN: 1995-0722.

Khal, A.; Ruszkiewicz, B. \& Mears, L. (2016). Springback evaluation of 304 stainless steel in an electrically assisted air bending operation. ASME $201611^{\text {th }}$ International Manufacturing Science and Engineering Conference, Virginia, USA, pp. 11-17. ISBN: 978-0-7918-4989-7.

Lange, K. (1994). Handbook of Metal Forming, McGraw Hill Book, New York.

Mohammadi, S.V.; Parsa, M.H. \& Aghchai, A. J. (2015). Simplified springback prediction in Al/PP/Al sandwich air bending. Journal of Sandwich Structures and Materials, Vol.17, No.3, pp. 217-237, ISSN: 1099-6362.

Ramadass, R.; Sambasivam, S. \& Thangavelu, K. (2019). Selection of optimal parameters in V-bending of Ti-Grade 2 sheet to minimize springback. Journal of the Brazilian Society of Mechanical Sciences and Engineering, Vol. 41, No.1, pp. 332343, ISSN: 1678-5878.

Shakir, M.G. \& Abbass, M.T. (2012). Finite Element Analysis of Sheet Metal UBending Using Free Form Surface. Engineering \& Technology Journal, Vol. 30, No.14, pp. 2431-2442, ISSN: 1681-6900.

Tekaslan, Ö.; Gerger, N. \& Seker, U. (2008). Determination of spring-back of stainless steel sheet metal in "V" bending dies. Materials \& Design, Vol.29, No.5, pp. 10431050, ISSN: 0261-3069.

Zhang, Y.; Jiang, J. \& Liu, Y. (2013). Theoretical analysis and experimental study of springback mechanism of archwire bending. Research Journal of Applied Sciences, Engineering and Technology, Vol. 6, No.13, pp. 2495-2501, ISSN: 2040-7459. 